\title{
Escasez de vínculos débiles: el atraso económico de la Andalucía con- temporánea desde la perspectiva de redes empresariales*
}

\author{
Juan Antonio Rubio-Mondéjar ${ }^{1}$ \\ Universidad de Granada \\ jarubio@ugr.es
}

Jósean Garrués-Irurzun ${ }^{2}$

Universidad de Granada

jgarrues@ugr.es

RESUMEN: Las redes empresariales, al favorecer la transmisión de ideas e innovaciones, así como la acumulación de capital, son un elemento que impulsa el desarrollo económico en el largo plazo. Pero, en última instancia, no son más que reflejo de las condiciones institucionales y económicas de un territorio. En este trabajo se presenta un estudio de las redes empresariales que actuaron en Andalucía en el periodo comprendido entre las décadas de 1880 y 1950. Una vez identificadas estas redes, se describen y se reflexiona sobre su relación con el crecimiento económico de la región. La investigación se basa en la información contenida en los libros de sociedades de los registros mercantiles de las ocho provincias andaluzas, sobre la que se ha aplicado la metodología de análisis de redes sociales. Frente a otros trabajos que se limitan a describir los indicadores estadísticos de las redes, aquí se recurre al análisis cualitativo de las mismas, así como de los empresarios que las formaron. Así, se encuentran dos razones que explican que las redes andaluzas no fueran un factor suficiente de desarrollo regional: primero, porque apenas contaron con «vínculos débiles»; segundo, porque no pudieron operar en los sectores más dinámicos de la economía de la región.

* Este trabajo se ha realizado en el marco del Proyecto «El sustento de la humanidad y la sostenibilidad de su entorno: cambios y permanencias en los procesos productivos (19302010)», financiado por el Ministerio de Economía y Competitividad (HAR2013-40760-R).

Los autores desean agradecer dicha financiación pública, así como los comentarios recibidos por parte de los evaluadores anónimos de Hispania.

1 ORCID iD: http://orcid.org/0000-0003-3843-5029.

2 ORCID iD: http://orcid.org/0000-0002-9261-5138. 


\section{PALABRAS CLAVE: Redes empresariales; desarrollo regional; Andalu- cía; historia económica; vínculos débiles; análisis de redes.}

\section{A shortage of weak ties: economic backwardness in contemporary Andalusia from a business-network perspective}

ABSTRACT: Business networks act as a driving force in long-term economic development, since they favour the transmission of ideas and innovation, as well as capital accumulation. But ultimately, networks are merely a reflection of the institutional and economic conditions of a country. This paper presents a study of business networks active in Andalusia in the period between the 1880s and 1950. First, we explain their characteristics and then reflect on their relationship with economic growth in the region. The research is based on information contained in the corporate books of business registers of Andalusia's eight provinces, to which the of social network analysis methodology has been applied. While other articles merely describe the statistical indicators of networks, here we resort to qualitative analysis thereof, as well as of the businessmen comprising them. We find two reasons why Andalusian networks were not a sufficient factor in regional development: firstly, because the networks had virtually no "weak ties»; secondly, because they could not operate in the most dynamic sectors of the economy.

KEY WORDS: Business Networks; Regional Development; Andalusia; Economic History; weak links; social network analysis.

CÓMO CITAR ESTE ARTÍCULO/CITATION: Rubio Mondéjar, Juan Antonio y Garrués Irurzun, Jósean, «Escasez de vínculos débiles: el atraso económico de la Andalucía contemporánea desde la perspectiva de redes empresariales», Hispania, 77/257 (Madrid, 2017): 793-826. doi: 103989/hispania.2017.022.

\section{INTRODUCCIÓN}

En los últimos años se ha reavivado el debate sobre el papel de los empresarios en el desarrollo económico de Andalucía ${ }^{3}$ : frente a las visiones tradicionales de las décadas de los ochenta y noventa del siglo pasado, ya no se responsabiliza al empresariado del atraso histórico de la región, más bien se

3 PAREJO, 2011: 11-23; 2009; 2006: 425-448. BERNAL, FLORENCIO y MARTÍNEZ, 2010. GARRUÉS, RUBIO y HERNÁNDEZ, 51 (Barcelona, 2013): 109-142.

El debate sobre el papel de los empresarios en los procesos de industrialización no es exclusivo de la historiografía andaluza. Para el conjunto de España, véase TORTELLA, 1996: 49-60. NADAL y SUDRIÀ, 3 (Barcelona, 1993): 199-227. VALDALISO, 2005: 115-145. VALDALISO y GARCÍA RUIZ, 51 (Barcelona, 2013). 
pone el acento en las condiciones del entorno. Así, una región periférica de Europa, alejada de los principales centros económicos, con grandes desequilibrios en el reparto de la renta y de la riqueza, y bajos niveles de alfabetización, sumados a una institucionalidad débil, no era la más idónea para afrontar con éxito una industrialización que, en los dos últimos siglos, se ha revelado como la vía fundamental para lograr el desarrollo económico. A este entorno socioeconómico y cultural complicado debieron adaptarse los empresarios andaluces, que tampoco pudieron explotar las posibilidades de la riqueza minera de la región, en manos de compañías foráneas con mayores capacidades técnicas, financieras y un mejor conocimiento de los mercados internacionales. El resultado fue una empresarialidad andaluza, medida a través de indicadores cuantitativos, inferior no solo a la de las regiones líderes, sino a la media del país ${ }^{4}$.

Desde un nuevo enfoque, que parte de la idea de que la empresarialidad no es una capacidad individual sino que reside en la interacción de capacidades colectivas, algunos trabajos han constatado que, pese a las limitaciones, entre 1880 y 1960 operó en Andalucía una gran red de creación de sociedades ${ }^{5}$. Pero, más allá del análisis agregado de la red, no han respondido a preguntas como cuáles fueron sus características o cuál fue su contribución al crecimiento económico de la región.

Con el ánimo de comprender mejor la incidencia de los empresarios en el desarrollo regional, el presente artículo desciende al análisis agregado de la red de emprendedores, la descompone para encontrar sus rasgos más destacados, y formula una hipótesis: la red andaluza presentó una grave carencia de lo que, en Sociología, se denominan vínculos débiles ${ }^{6}$, aquellos que más importancia tienen para el intercambio de ideas innovadoras e información de calidad para explotar las oportunidades de una economía que, en sí, ya estaba seriamente limitada.

\section{DATOS, METODOLOGÍA Y TEORÍA DE REDES}

La investigación sobre la red de emprendedores andaluces se basa en los registros mercantiles de las ocho provincias andaluzas, en el periodo 18861959. Dichos registros fueron vaciados y su información depurada y sistematizada en la base de datos denominada SERMA, acrónimo de Socios y Empresas del Registro Mercantil de Andalucía ${ }^{7}$.

4 RUBIO, 2014.

5 GARRUÉS, RUBIO y HERNÁNDEZ, 51 (Barcelona, 2013): 109-142. GARRUÉS y RUBIO, 2013: 139-161; 404 (Barcelona, 2012). RUBIO, 2015: 151-163.

6 GRANOVETTER, 78 (Chicago, 1973): 1.360-1.380.

7 El proyecto de elaboración de la base de datos estuvo coordinado por los profesores Martín, Garrués y Hernández (Universidad de Granada). 
Los libros de sociedades de los registros mercantiles constituyen una fuente de naturaleza jurídica que ha sido ampliamente utilizada por la historiografía española, sobre todo a partir de la publicación en 1974 de un artículo de Jiménez Araya sobre formación de capital y ciclos económicos, basado en la estadística oficial elaborada a partir del contenido de dichos libros ${ }^{8}$. Sus características, virtudes y debilidades, han sido expuestas en numerosos trabajos ${ }^{9}$.

Tradicionalmente, en España las compañías mercantiles se creaban mediante acuerdos verbales o ante notario. El Código de Comercio de 1885 estableció la obligatoriedad de inscribir los principales actos de la vida jurídica de las sociedades en un registro público, con el propósito de incentivar la actividad empresarial. Esto supuso que, desde 1886, en cada capital de provincia funcionara un registro provincial, en el que se inscribían las compañías previamente constituidas ante notario. La inscripción era obligatoria, y las sociedades debían registrar, entre otros datos, su nombre o razón social, la clase de comercio o el tipo de operaciones que pretendían desempeñar y la fecha de inicio de las mismas; el domicilio o las escrituras de constitución. Las sociedades también debían inscribir las modificaciones del contrato de constitución, la rescisión, disolución, reactivación, transformación, fusión o escisión. Además de los registros provinciales, el Código de Comercio de 1885 ordenaba la creación de un Registro Mercantil central que recogiera la información procedente de los Registros Provinciales y que, con carácter anual, publicara una Estadística con el número y capital de las sociedades constituidas y disueltas en el país ${ }^{10}$.

Frente a estos resúmenes, la consulta directa de los libros de sociedades aumenta sustancialmente las posibilidades del Registro Mercantil como fuente histórica, ya que permite la depuración de los datos para obtener indicadores más fiables y proporciona información cualitativa sobre la actividad de las compañías y de las personas que intervenían en los actos jurídicos de las mismas.

\section{Análisis de redes y empresarialidad}

Metodológicamente, la investigación se apoya en el análisis de redes sociales, un conjunto de herramientas teóricas e instrumentales que permiten conocer la estructura de una red. El análisis de redes sociales, que surge a partir de la teoría de grafos, se introduce en la Sociología en la segunda mitad

8 JIMÉNEZ ARAYA, 27 (Barcelona, 1974): 137-185.

9 Las posibilidades que ofrece el registro mercantil para la historiografía, en MARTÍN, GARRUÉS y HERNÁNDEZ, 2003. TAFUNELL, 2005: 707-834.

10 Las Estadísticas fueron publicadas en 1901, con datos de 1886-1898; en 1911, con información del periodo 1899-1909; y anualmente, desde 1912 hasta la actualidad. 
del siglo XX, pero su aplicación a la literatura científica se ha acelerado en la última década, con el desarrollo de sofisticados programas de software que facilitan los cálculos de indicadores estadísticos, y que han contribuido a popularizar su utilización en disciplinas distintas de la Sociología ${ }^{11}$. En el campo de la Historia, la celebración de la Historical Network Research Conference, evento anual internacional que comenzó en 2013, evidencia la novedad y las posibilidades del análisis de redes ${ }^{12}$. Aunque la historiografía española cuenta con numerosos estudios cualitativos sobre redes personales, apenas ha hecho uso de las herramientas de análisis de redes sociales, si descontamos algunos trabajos relacionados con consejeros comunes y con el estudio de la élite empresarial en el largo plazo ${ }^{13}$.

Una crítica habitual al análisis de redes insiste en que únicamente proporciona parámetros estructurales, indicadores de la densidad de la red y medidas de la centralidad de sus actores. Para subsanar este defecto, en los últimos años se ha demandado una mayor preocupación por la configuración de las redes en los estudios empíricos que abordan la relación entre redes y empresarialidad o capital social ${ }^{14}$.

La empresarialidad - término difuso que se refiere a la capacidad para la creación de empresas y la innovación - se ha considerado habitualmente una cualidad individual, no colectiva. Pero la realidad es que toda actividad económica está coordinada por grupos de personas, no por individuos aislados, ya que la acción económica está enraizada en redes de relaciones personales, que conforman las instituciones y determinan la evolución de los sectores y las empresas ${ }^{15}$.

Desde el punto de vista teórico, las redes son un componente fundamental del capital social, y se presentan como una alternativa eficiente a la empresa y al mercado, debido a que reducen los costes de transacción ${ }^{16}$. Las redes personales, construidas a partir de relaciones de confianza - basadas en un origen familiar, cultural, geográfico o étnico común - facilitan el funcionamiento de los grupos empresariales ${ }^{17}$, y esto ocurre tanto en economías en vías de desarrollo como en economías avanzadas ${ }^{18}$. Además, las redes favorecen la

11 BORGATTI, HALGIN, 22 (New York, 2011): 1.168-1.181.

12 Una evaluación del análisis de redes como metodología para historiadores, en BERTRAND, GUZZI-HEEB y LEMERCIER, 21/1 (Barcelona, 2011): 1-12.

13 Véase, por ejemplo, BADÍA, BLASCO, LOZANO y SOLER, 9 (Madrid, 2013): 143154. RUBIO y GARRUÉS, 58 (Oxford, 2016).

14 CASSON y DELLA GIUSTA, 25 (New York, 2007): 220-244. CASSON, 2010b: 14-40.

15 GRANOVETTER, 35 (New York, 1992): 3-11.

16 CASSON, 26/2 (Williamsburg, 1997): 811-823.

17 LEFF, 26 (Chicago, 1978): 661-675.

18 GRANOVETTER, 35 (New York, 1992): 8, se opone a quienes consideran que los 
adopción de innovaciones tecnológicas y organizativas, impulsando la empresarialidad $^{19}$.

Casson ha definido las redes como «conjuntos de relaciones de alta confianza», que garantizan la transferencia de información a un menor coste y con mayor calidad que las empresas y los mercados; a la triple distinción de Douglass North entre empresas, mercado y Estado, el historiador y economista británico añade las redes como un cuarto tipo de institución, para después afirmar que las empresas y los mercados no son una alternativa a las redes, sino que simplemente constituyen tipos de redes ${ }^{20}$. Una característica importante de estas es que siempre forman parte de un sistema más amplio, conectan elementos de diferentes redes y forman una red global ${ }^{21}$.

Las redes sociales coordinan los flujos de información que permiten a los emprendedores identificar las oportunidades de beneficio, adquirir recursos para explotarlas, y hacer esto de manera óptima ${ }^{22}$. Pero cada fase de la actividad emprendedora requiere un tipo determinado de redes, por lo que es muy importante conocer cómo se articulan. Sus aspectos formales deben ser analizados, puesto que si las redes están definidas por la naturaleza de las conexiones entre sus actores, para comprenderlas hay que conocer su configuración, o lo que es lo mismo, el modo en que aquellos se conectan ${ }^{23}$. Además de la configuración, otros tres elementos son claves en la estructura de las redes: el tamaño, entendido como el número de actores que comprenden; la diversidad, que se refiere a los distintos tipos funcionales de actores; y la naturaleza de las relaciones - formales/informales, internas/externas - que los conectan.

Estos elementos - configuración, tamaño, diversidad y naturaleza de las relaciones - se pueden estudiar a través de la combinación de indicadores estadísticos y de investigación cualitativa sobre los actores que participan en la red. Los principales indicadores estadísticos utilizados en los análisis de redes son los siguientes:

- Componente: es una parte de la red, un conjunto de actores que están conectados entre sí pero que no están vinculados a otros componentes.

- Densidad: cociente entre el número de relaciones existentes entre los actores y el número de relaciones potenciales entre los mismos.

\footnotetext{
grupos empresariales basados en relaciones personales desaparecen a medida que los mercados ganan en complejidad.

19 PARSON y ROSE, 2010: 41-60.

20 Véase CASSON, 2010a.

21 Esta concepción sistémica, en la que unas redes están envueltas en otras redes que abarcan todos los aspectos de la sociedad, es la misma que utilizan McNEILL y McNEILL (2004), en su estimulante historia de la humanidad.

22 CASSON, 2010b: 14-40.

23 CASSON y DELLA GIUSTA, 25 (New York, 2007): 227.
} 
- Índice de centralización (centralization network index): indica la dependencia de la red con respecto a los actores más centrales de la misma: a mayor índice, mayor relevancia estructural de estos.

- Centralidad (degree): número de actores con los que está vinculado cada actor.

- Grado de intermediación (betweenness centrality): capacidad de un actor para conectar a otros dos actores ${ }^{24}$.

Los dos últimos parámetros — centralidad y grado de intermediaciónpermiten caracterizar a los actores individualmente, pero también al conjunto de la red, cuando se obtiene el promedio de los valores individuales.

La literatura sobre redes empresariales resalta la importancia de estos indicadores para definir el carácter de la red, en función de su capacidad para controlar y transmitir los flujos de información. En un estudio comparativo sobre redes de consejeros comunes de grandes empresas de la actualidad, Cárdenas distingue entre dos tipos de redes corporativas: elitistas, basadas en la centralización y el control, y pluralistas, que se basan en la descentralización y la eficiencia ${ }^{25}$.

Las redes elitistas son densas, muestran una alta dependencia con respecto a los actores más centrales - que, al mismo tiempo, presentan elevados índices de centralidad y de intermediación - y suelen estar articuladas a partir de un único componente $\mathrm{o}$, en su defecto, de un número reducido de componentes. Esta configuración permite así que un limitado grupo de actores sea indispensable para su funcionamiento.

En cambio, las redes pluralistas se caracterizan por tener menores índices de densidad y cohesión, no ser tan dependientes de los actores principales, y contener una mayor variedad de componentes. Más que el control de la información de las oportunidades de negocio o de las estrategias empresariales, en las redes pluralistas prima la eficiencia de la transmisión de estos conocimientos.

Desde el punto de vista de la configuración se han descrito numerosos tipos de redes, si bien los más usuales son tres ${ }^{26}$ :

- Hub: es una red en la que un único actor ocupa la posición central y conecta entre sí a todos los demás.

24 Una explicación detallada y actualizada de las medidas, en WASSERMAN y FAUST, 2013.

25 CÁRDENAS, 53 (Dorchester, 2012): 298-322.

26 Una descripción de los diferentes tipos de configuración, en CASSON y DELLA GIUSTA, 25 (New York, 2007): 226-228. 
- Branch: los actores centrales de distintas redes hubs se conectan entre sí; la información se transmite a los miembros de cada una de las subredes, pero la comunicación entre los grupos está controlada por sus cabecillas.

- Web: es una red en la que la mayor parte de sus actores se conectan con el resto de los actores de la misma, sin que existan figuras principales que controlen la información. En este tipo de configuración, al contrario que en los anteriores, no existen factores decisivos que, en caso de desaparecer, interrumpan los flujos de comunicación.

Siguiendo el esquema de Cárdenas, las redes tipo web estarían más cerca del modelo de redes pluralistas, mientras que las tipo hub o branch se corresponderían con redes elitistas.

Otra cuestión importante en relación con la configuración de la red es la distancia entre los actores. Cuando más próximos se encuentren desde el punto de vista estructural - es decir, cuantos menos actores intermediarios los separen-mayor será la calidad de la transferencia de información ${ }^{27}$.

El estudio de la configuración de las redes permite dar un paso importante en la comprensión de las mismas, superando el mero análisis de los indicadores de centralidad. No obstante, esta información es insuficiente si no se completa con el análisis cualitativo de los actores y de las relaciones que los unen. En relación con la empresarialidad, la observación de los actores permite identificar distintas funcionalidades: hay socios de las empresas que descubren la oportunidad de negocio, mientras que otros aportan conocimiento técnico o contactos políticos; otros contribuyen con el capital, o destacan por su capacidad para movilizar a quienes pueden sumar capital.

El análisis conjunto de la posición estructural en la red y de las características individuales de los socios permite identificar actores que son especialmente relevantes para el funcionamiento de la red, por su potencial para ofrecer información diferente y trascendental: se trata de los «vínculos débiles». De acuerdo con Granovetter ${ }^{28}$, la calidad de la red dependerá de la mayor presencia de estos «vínculos débiles», individuos que presentan unos rasgos distintos a los de la mayor parte de los actores de la red. Cuanto más tengan en común dos personas - parentesco, institución educativa, círculo de amistades, tipo de formación - más homogénea será la información que puedan compartir, lo que limitará la transmisión de ideas innovadoras. En cambio, personas alejadas de estos círculos presentarán un mayor potencial de innovación.

27 La cercanía entre los actores permite crear «mundos pequeños» en la red, subgrupos en los que se concentra la información más relevante. El concepto de small world en MILGRAM, 1 (New York, 1967): 61-67.Véase también WATTS, 2003.

28 GRANOVETTER 78 (Chicago, 1973): 1.360-1.380. 
En el análisis de las redes endógenas de creación de empresas en Andalucía que se expone en el apartado siguiente se ha tratado de conjugar todos estos elementos, cuantitativos, estructurales y cualitativos, para comprender su incidencia en el desarrollo regional.

\section{LA RED EMPRESARIAL ANDALUZA, 1886-1959}

Después del agotamiento de la primera revolución industrial, y tras un periodo de varias décadas de debilidad del crecimiento económico global, una serie de innovaciones técnicas concentradas en nuevos sectores industriales dio paso a lo que se conoce como segunda revolución tecnológica. Esta segunda fase del desarrollo económico moderno tuvo como pilares básicos los combustibles fósiles, la energía eléctrica, el motor de explosión y las industrias química y automovilística.

En Andalucía, la segunda revolución tecnológica tuvo lugar entre las décadas de 1880 y 1960. Sin embargo, la implantación de las transformaciones económicas asociadas a este periodo fue débil y, en líneas generales, mantuvo una intensidad inferior a la media de España. El PIB, un indicador de la actividad económica (gráfico 1), muestra cómo desde el inicio del siglo XX la tendencia del crecimiento andaluz fue mucho menos pronunciada que la del conjunto del país. El profesor Parejo ha insistido en que el atraso relativo de la región se produjo en los años inmediatamente posteriores a la Guerra Civil, si bien otros trabajos apuntan a una pérdida progresiva del peso económico de Andalucía, muy visible ya desde la Primera Guerra Mundial ${ }^{29}$. En cualquier caso, ambas interpretaciones son complementarias, y señalan cómo el proceso de modernización económico andaluz fue de menor calado que el de la media nacional. Las explicaciones vuelven a recaer en la desigual distribución de la riqueza y el menor nivel de alfabetización de la población, así como en elementos relacionados con los productos andaluces y su vinculación con los mercados internacionales. El ocaso de la minería andaluza, las políticas proteccionistas asumidas por la mayoría de los países en los años veinte, las consecuencias en los mercados internacionales de la crisis de los treinta, y el aislamiento franquista perjudicaron gravemente al sector más dinámico de la economía, aquel que tenía un marcado carácter exportador.

29 PAREJO, 2009. RUBIO, 2015. La Primera Guerra Mundial brindó a los países neutrales importantes oportunidades de negocio, debido tanto a que los países contendientes se retiraron de los mercados internacionales como oferentes de productos, concentrados en el esfuerzo bélico, como a la necesidad de los mismos de importaciones para satisfacer la demanda de sus poblaciones y de sus efectivos militares. Pero, dentro de los países neutrales, existieron regiones que pudieron aprovechar mejor estas nuevas oportunidades. La formación del capitalismo español durante el conflicto mundial, en ROLDÁN, GARCÍA DELGADO y MUÑOZ, 1973. 
GRÁfICO 1. Comparación del PIB de España y Andalucía (en millones de pesetas de 1995)

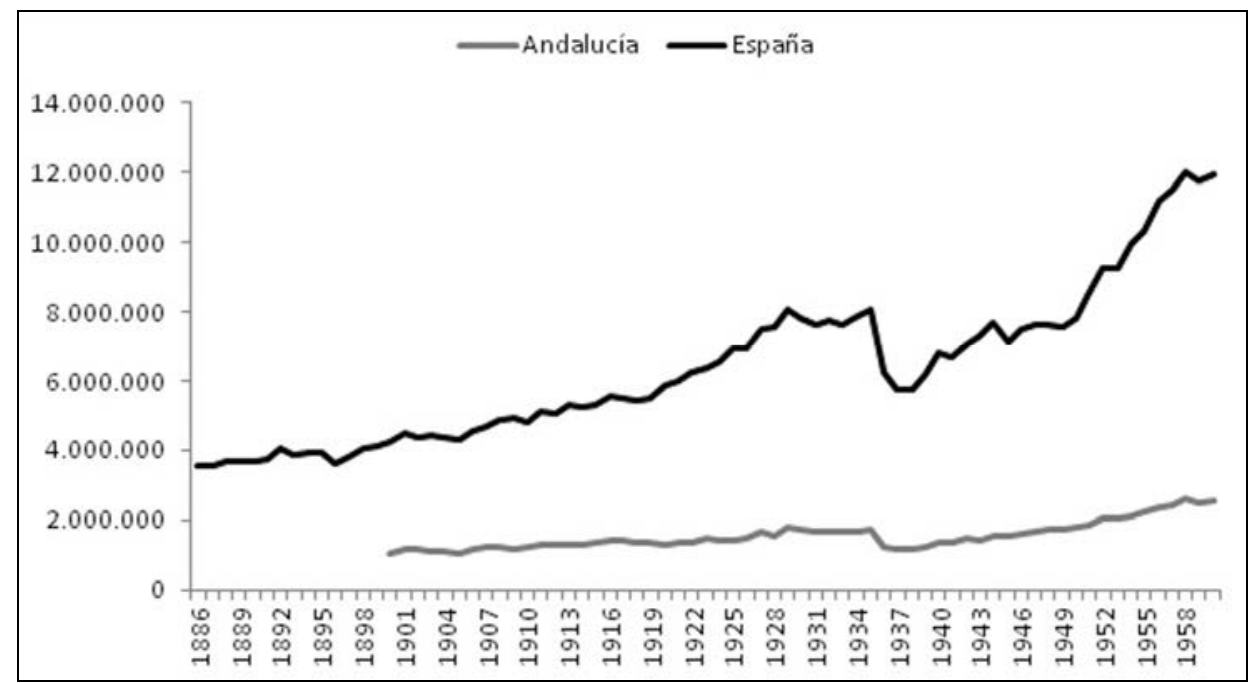

Fuente: los datos de España en PRADOS DE LA ESCOSURA (2003). Los de Andalucía, en LIZÁRRAGA (2009).

\section{La «gran red»}

Cuando se aplica la metodología del análisis de redes sociales a los socios fundadores de las empresas creadas en Andalucía entre 1886 y 1959, se identifica una red social de grandes dimensiones. De los más de 25 mil socios que tomaron parte en escrituras de constitución, alrededor de tres mil repitieron en más de una sociedad. De ellos, 1.745 formaron parte de la red empresarial andaluza, divididos en 69 componentes o grupos de individuos relacionados entre sí. El mayor de los componentes conectó a 1.402 socios, el $80 \%$ de los actores de la red. El segundo y tercer componente, en cambio, sólo estaban formados por 24 y 22 socios, respectivamente.

Otros trabajos han explicado las principales características de la red de creación de empresas que operó en la región antes de 1959, así como su evolución a lo largo del tiempo ${ }^{30}$. Por ellos se conoce que, desde el punto de vista

30 La descripción de la red, desde el punto de vista estructural, en GARRUÉS y RUBIO, XVI/404 (Barcelona, 2012). GARRUÉS, RUBIO y HERNÁNDEZ, 51 (Barcelona, 2013): 109-142. En el último artículo también se estudian las características de los individuos que conformaron la red (relaciones de parentesco, nivel de estudios y profesión, edad, origen geográfico y vínculos con la política). 
estructural, la red sufrió una ruptura con la Guerra Civil. Después del conflicto bélico, la red aumentó en tamaño (medido tanto en número de socios como de compañías creadas), y el número de socios que formaron parte del componente principal también creció considerablemente. Sin embargo, el índice de centralización y la centralidad media de la red disminuyeron, sobre todo en comparación con el periodo anterior a 1913 (cuadro 1) ${ }^{31}$.

CUADRO 1. Indicadores estadísticos de la red de creación de empresas andaluzas, 1886-1959

\begin{tabular}{lccc}
\hline INDICADORES & $\mathbf{1 8 8 6 - 1 9 1 3}$ & $\mathbf{1 9 1 4 - 1 9 3 5}$ & $\mathbf{1 9 3 6 - 1 9 5 9}$ \\
\hline Socios Red & 677 & 400 & 938 \\
$\mathbf{N}^{\mathbf{0}}$ Componentes & 110 & 77 & 128 \\
Socios del Mayor Componente & 285 & 169 & 465 \\
Sociedades creadas & 423 & 272 & 645 \\
Densidad (x100) & 1,0 & 0,8 & 0,9 \\
Grado de Centralidad & 8,08 & 4,55 & 6,59 \\
Índice de Centralización & 1,93 & 1,68 & 0,99 \\
Grado de Intermediación & 0,15 & 0,31 & 0,11 \\
\hline
\end{tabular}

Fuente: elaboración propia.

Otra diferencia entre ambos periodos es que, durante los veinte años transcurridos desde el final de la Guerra Civil, la red se concentró en la mitad occidental de la región, convirtiéndose Sevilla en el centro neurálgico de la misma, frente a la etapa anterior en la que, en términos relativos, había compartido protagonismo con núcleos orientales como los de Granada, Málaga, o incluso el distrito minero Linares-La Carolina ${ }^{32}$. La red, como indicador de la actividad empresarial, reflejaba una nueva realidad: pasado el boom del azúcar, con una minería en declive y la reagrarización de la economía andaluza, las iniciativas empresariales más importantes se ubicaron en la capital de la región, Sevilla, que también era el núcleo urbano de mayor tamaño ${ }^{33}$.

Pero el análisis de redes no se limita al estudio agregado de la red, sino que proporciona herramientas para conocer el papel desempeñado por los actores, los empresarios; esto se ha hecho, obteniendo tres indicadores rela-

31 Las medidas de centralidad se han explicado en el apartado anterior.

32 GARRUÉS y RUBIO, XVI/404 (Barcelona, 2012).

33 Véase PAREJO, 2009. BERNAL, FLORENCIO y MARTÍNEZ RUIZ, 2010. RUBIO, 2014. 
cionados con los socios: grado de centralidad, grado de intermediación y centralidad de vector propio de Bonacich ${ }^{34}$. Los resultados corroboran lo que ya se conocía, pero añaden matices: los actores más centrales de la etapa 18861913 pertenecieron, mayoritariamente, al distrito azucarero de Granada, lo que se explica por las altas exigencias de capital del sector, que implicaban la participación de un número elevado de $\operatorname{socios}^{35}$; los granadinos desempeñaron así un papel fundamental en la configuración del componente principal de la red. En el periodo 1914-1935 aumentó el protagonismo de los socios sevillanos, que ocuparon las veinte primeras posiciones en cuanto a centralidad de vector propio. En la última etapa, tras la Guerra Civil, los mayores valores de los tres indicadores estuvieron copados por socios residentes en Sevilla, Cádiz y Jerez de la Frontera. Los empresarios jerezanos fueron los mejor conectados, en un momento en el que se recuperaron las ventas y las exportaciones relacionadas con la especialización vitivinícola, tras seis décadas de caída ${ }^{36}$. La vinculación entre los socios sevillanos y jerezanos fue muy estrecha, y se extendió a distintos sectores de actividad, entre los que destacaron el complejo agroalimentario (explotaciones agropecuarias y la industria de transformación asociada a ellas) y el sector de la construcción inmobiliaria.

Además de lo dicho, el análisis de la centralidad de los individuos descubre el cambio generacional que se produce entre los socios de las empresas tras la Guerra Civil, apareciendo nuevos actores que, aunque en la mayoría de los casos contaban con antecedentes familiares en el ámbito empresarial andaluz, en este momento ocuparon las posiciones centrales del componente principal. El elemento familiar, presente en las dos etapas anteriores a 1936, se hizo más visible después de esta fecha. En las clasificaciones de los socios en función de los indicadores es habitual que, entre las primeras posiciones, se repitan apellidos como González Gordon, Fernández de Bobadilla, Beca, Benjumea o Quijano. Este hecho se explica por la extensión de nuevas formas de organizar la actividad societaria, como la generalización de la sociedad anónima, el reparto del capital accionarial entre miembros de una misma familia, la configuración de grupos empresariales y la aparición de grupos inversores ${ }^{37}$.

La posición de los actores en la estructura de la red, por lo tanto, es una cuestión importante: la transmisión de la información, de acuerdo con la popular teoría de los «seis grados de separación», configura «mundos peque-

34 El grado de centralidad y el de intermediación han sido explicados en la sección anterior; la centralidad de vector propio mide la capacidad de un actor de relacionarse con los actores mejor conectados de la red.

35 El desarrollo del sector azucarero en Granada, en MARTÍN, 1982; 2009.

36 LIGNON-DARMAILLAC, 2004.

37 Estos cambios hicieron que, por primera vez, aparecieran mujeres con medidas de centralidad significativas. 
ños» en el interior de la red ${ }^{38}$; los socios que ocupaban posiciones más centrales contaban con ventajas sobre los demás. Casi todos los socios con mayores medidas de centralidad se ubicaron en el componente principal. Hubo, no obstante, nombres ilustres del empresariado andaluz, como los hermanos Carbonell Morand (del grupo agroalimentario Carbonell) o miembros de la familia Larios, como José A. Larios o Enrique Crooke Larios, que se encontraban en componentes secundarios de la red, si bien no fueron más que excepciones $^{39}$, ya que el componente principal agrupó a la mayor parte de los empresarios e inversores más destacados de la región.

El análisis combinado de los indicadores de la red y de los de sus socios ofrece otro nuevo elemento: la escasa presencia de lo que se conoce como «vínculos débiles», actores que, compartiendo pocas características comunes con los demás, permiten el acceso a la información más valiosa ${ }^{40}$. Cuando se habla de la creación de empresas en un periodo como la segunda revolución industrial, los «vínculos débiles» serían individuos que ayudarían a descubrir oportunidades de negocio, por sus conocimientos en un sector tecnológicamente novedoso, relaciones con el mundo de la gran empresa, con otras regiones o países más avanzados, etc. Sin embargo, los «vínculos débiles» en la red andaluza fueron pocos, menos de los que precisaba el momento histórico, lo que constituye un elemento más para comprender las limitaciones del crecimiento económico de la región. No se trata de que Andalucía se mantuviera en el subdesarrollo relativo por carecer de vínculos débiles, sino de que la ausencia de este tipo de conexiones refleja la debilidad del marco empresarial e institucional de la región en un contexto que requería adaptabilidad a las nuevas transformaciones económicas.

En el gráfico 2 puede verse la posición de uno de estos «vínculos débiles», el ingeniero Alfredo Velasco, en el componente principal de la red de 18861913. Velasco, que inició su carrera empresarial en la región como directivo de las compañías y hombre de confianza del empresario zaragozano Nicolás de Escoriaza ${ }^{41}$, ejemplifica el concepto de «vínculo débil»: ajeno a Andalucía, sin relaciones personales previas con los miembros de la red en la que se inserta, y un nivel educativo por encima de la media; además, su posición en la red es decisiva, pues fue uno de los puntos de corte que unía a los dos núcleos más importantes del componente principal, que se escindiría en dos sin su presencia. Más adelante se retomará la importancia de los vínculos débiles.

38 MILGRAM, 1 (New York, 1967): 61-67.

39 En ambos casos, se trataba de decisiones conscientes de los grupos empresariales familiares, que no necesitaban financiación externa para sus proyectos; JIMÉNEZ BLANCO, 1203 (Madrid, 2012), ha explicado esta estrategia para el grupo empresarial de los Larios. También puede verse PAREJO, 1990. La casa Carbonell en CASTEJÓN, 1977.

40 GRANOVETTER, 78 (Chicago, 1973): 1.360-1.380.

41 La biografía empresarial de Velasco, en NÚÑEZ, $5 / 5$ (Granada, 2005). 
GRÁFICO 2. Velasco Sotillos en la Red de 1886-1913

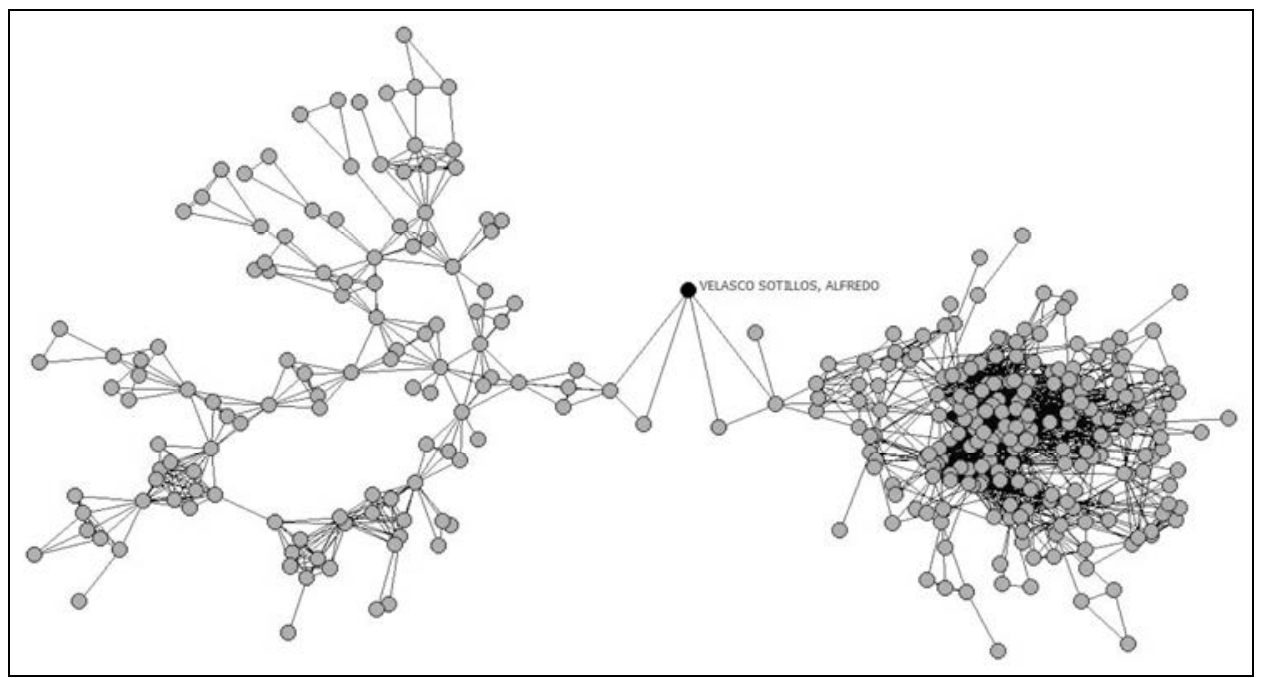

Fuente: elaboración propia.

\section{Descomponiendo la red en redes}

La red de creación de empresas se ha definido a partir de la coincidencia de dos socios en la constitución de una sociedad mercantil. Pero esta red se puede descomponer en subredes, o redes más pequeñas, empleando un criterio más restrictivo, que es la participación de los socios en un mínimo de tres empresas en común. Mientras que la confluencia en la creación de una única sociedad puede deberse a causas diversas, incluso al azar, un mínimo de tres iniciativas comunes significa continuidad de la cooperación a lo largo del tiempo.

Siguiendo este criterio, entre 1886 y 1959 existieron en Andalucía 84 subredes (a partir de ahora se denominaran simplemente «redes»); de ellas 57 fueron parejas, formadas por sólo dos socios. El análisis se ha centrado en las 27 redes de mayor tamaño - al menos tres socios con un mínimo de tres empresas en común - y en tres parejas que aportan elementos de estudio interesantes. 
ESCASEZ DE VÍNCULOS DÉBILES: EL ATRASO ECONÓMICO DE LA ANDALUCÍA CONTEMPORÁNEA …8 807

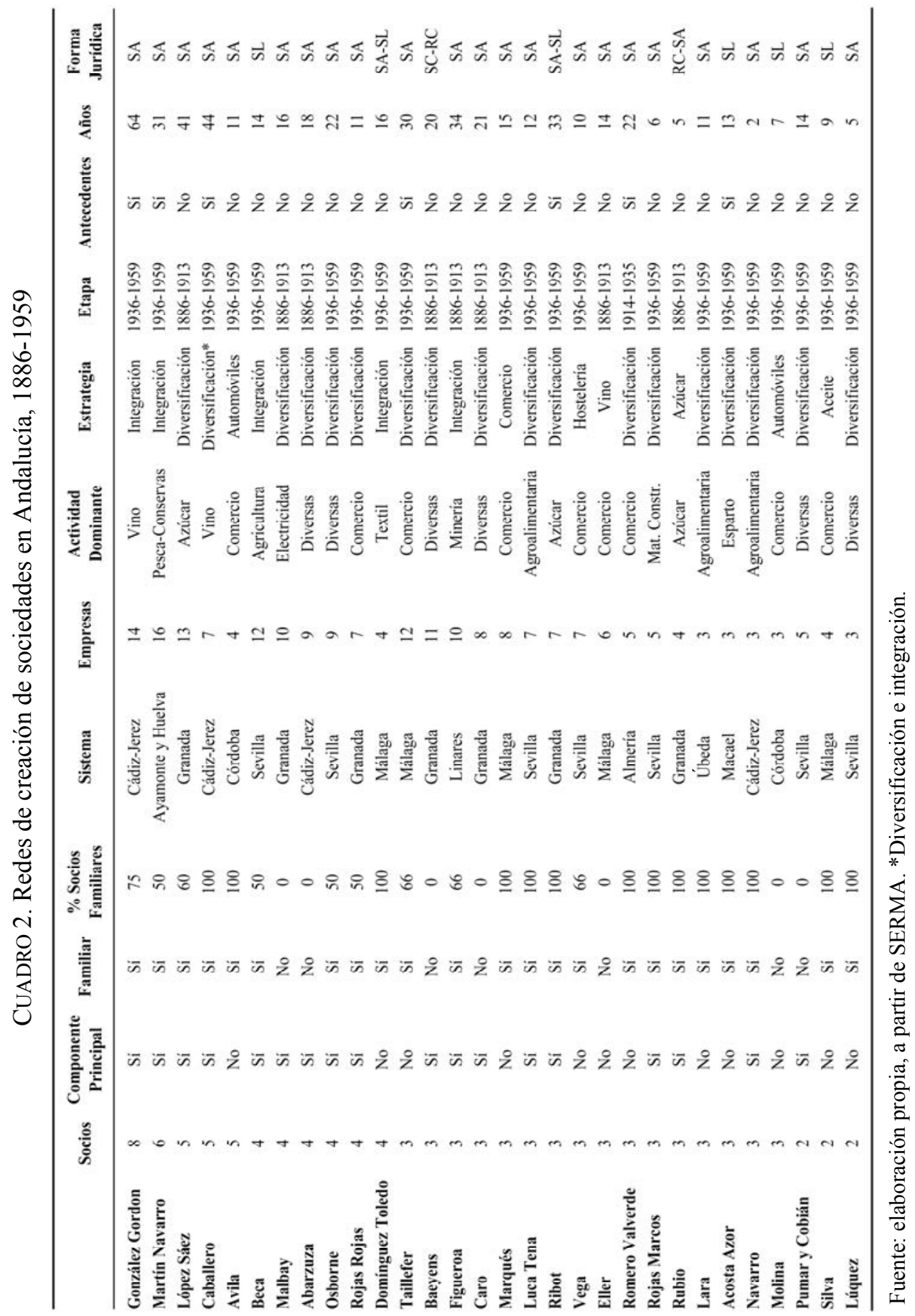

Hispania, 2017, vol. LXXVII, nº. 257, sept.-diciembre, págs. 793-826, ISSN: 0018-2141, e-ISSN: 1988-8368, doi: 10.3989/hispania.2017.022 
Las principales características de las redes andaluzas se resumen en el cuadro 2: el tamaño, medido en número de socios y de empresas creadas; la vinculación o no al componente principal de la red; el carácter familiar; el sistema empresarial en el que actuó mayoritariamente ${ }^{42}$; la actividad mercantil predominante y el tipo de estrategia empresarial que siguió -integración, diversificación o único sector-; el periodo en el que generó nuevas sociedades, los antecedentes previos y el número de años activa; $\mathrm{y}$, en último lugar, la forma jurídica más usual de las firmas.

\section{Carácter familiar}

Los elementos cualitativos permiten profundizar en la naturaleza y el comportamiento de las redes, más allá de las cuestiones estructurales. En este sentido, un aspecto fundamental es el papel de las relaciones familiares, que tiene un especial protagonismo en el caso de las redes empresariales ${ }^{43}$. Se ha establecido que una red tiene carácter familiar cuando al menos la mitad de sus miembros están unidos por vínculos de parentesco directos, es decir, padres-hijos, hermanos, primos, sobrinos o matrimonios ${ }^{44}$. Siguiendo este criterio, tres de cada cuatro redes fueron familiares, lo que indica que en el momento de desarrollar un proyecto empresarial los individuos recurrían a relaciones de alta confianza ${ }^{45}$, a los «vínculos fuertes». Una posibilidad es que la red familiar apoyara financieramente la idea de uno o varios de sus miembros. En algunos casos se trataba de estrategias organizativas de un grupo empresarial familiar, que creaba nuevas compañías mercantiles en las que tomaron parte los socios de las firmas matrices; en otros, de estrategias familiares para repartir la propiedad de las sociedades entre los descendientes del empresario, que vinculaba a las nuevas firmas incluso a sus hijos menores de edad; también se dio el caso, en las redes de inversión, que el descubrimiento de una oportunidad de negocio que se preveía rentable hiciera que la informa-

42 Por sistema empresarial se entiende un conjunto de localidades colindantes con una actividad económica común. Un análisis de los sistemas empresariales locales andaluces en el periodo estudiado y su relación con el desarrollo económico de la región, en RUBIO y GARRUÉS, 68 (Barcelona, 2017): 81-117.

43 FERNÁNDEZ PÉREZ (1997) subrayó la importancia del componente familiar en las redes mercantiles gaditanas que participaban en el comercio colonial. La empresa familiar y su vinculación al desarrollo económico en el largo plazo, en FERNÁNDEZ PEREZ y COLLI, 2013.

44 No se incluye, por tanto, a la familia política, salvo en el caso de los cónyuges.

45 ALFANI y GOURDON, 65 (Oxford, 2012): 1.005-1.028, ofrecen una visión de largo plazo de la relación entre empresarialidad y vínculos familiares en Europa, entre los siglos XIV y XX. 
ción se transmitiera a los miembros de la familia, para que estos se sumaran a la financiación de un proyecto ajeno.

Los lazos familiares son vínculos fuertes que, además de las virtudes ya mencionadas de acumular y transmitir capital social y financiero reduciendo el riesgo de iniciar un negocio, dotan a las redes de persistencia en el tiempo, porque favorecen el reemplazo de unos miembros por otros ${ }^{46}$. Pero hay que alertar, como hizo Granovetter en su momento, de la «debilidad de los vínculos fuertes»: dos personas que se han educado en los mismos valores y entorno cultural, han recibido la misma formación, han desempeñado la misma actividad económica, y frecuentan un mismo círculo de relaciones, están en posesión de una información muy similar, porque cuanto más fuerte es un vínculo más se parecen entre sí los dos individuos que lo comparten; la riqueza de la información que transmite la red, por tanto, depende de la «fortaleza de los vínculos débiles» ${ }^{47}$. El planteamiento de Granovetter es consistente si se aplica a la empresarialidad y al desarrollo económico. Un sistema empresarial como el andaluz, con un gran peso de los vínculos fuertes - no sólo los familiares, también relaciones de amistad - habría necesitado más vínculos débiles, que en los análisis de la estructura de la red y de la centralidad de sus actores serían aquellos individuos que posibilitarían la conexión entre los distintos grupos que originaban el componente principal. La presencia de esos actores que generalmente actuaban como representantes de intereses financieros o industriales ajenos a la región, cobra así un nuevo valor. Su escaso número sugiere, en cambio, un indicio de las dificultades modernizadoras del territorio andaluz, que debe relacionarse también con la limitada oferta de oportunidades de negocio.

En 1886-1913 fueron más numerosas las redes que no eran familiares, mientras que en 1936-1959 el dominio de las familiares fue casi absoluto. La diferenciación entre ambos periodos debe explicarse por los cambios socioeconómicos que hicieron más frecuente la formalización de sociedades mercantiles a medida que avanzaba el siglo XX — se constituían jurídicamente empresas familiares que, con anterioridad, no tomaban forma societaria-, pero, especialmente, por las características de la economía española en una y otra etapa: hasta la Primera Guerra Mundial, la apertura del país favorecía que una región con vocación exportadora, como la andaluza, se conectara a los mercados internacionales, lo que requería redes abiertas, que transmitieran conocimientos técnicos y comerciales; a partir de los años veinte $\mathrm{y}$, sobre todo, tras la Guerra Civil, el nacionalismo económico limitó las conexiones con el mercado exterior, dificultando el acceso a esos conocimientos, menos valio-

46 CASSON y DELLA GIUSTA, 25 (New York, 2007): 225. GRANOVETTER, 91 (Chicago, 1985): 481-510. Las redes más longevas, González Gordon y Caballero, tenían un marcado componente familiar.

47 GRANOVETTER 78 (Chicago, 1973): 1.360-1.380. 
sos en la nueva situación. Las restricciones que obligaban a las empresas a concentrarse en el mercado nacional condicionaban la forma y funcionalidad de las redes, más cerradas y basadas en círculos más íntimos.

De las cinco redes no familiares del periodo 1886-1913, tres estuvieron ubicadas en Granada: una (Malbay), formada por arquitectos e ingenieros - lo que determinaba la relación era la formación técnica de los socios-, y dos eran redes de inversores (Baeyens y Caro) ${ }^{48}$, que participaron en el boom del azúcar y en negocios relacionados con la minería y la electricidad, que precisaban conocimientos y capital; la cuarta, en Málaga, se dedicaba a la exportación de vinos (Eller) y contaba con dos socios de la zona y un extranjero; la quinta fue otra red de inversión (Abarzuza) formada por propietarios y comerciantes de Cádiz y Sevilla e implicada en la financiación de proyectos muy diversos, al margen de las actividades empresariales cotidianas de sus miembros. Después de 1936 sólo dos de las 21 redes no fueron familiares: la pareja Pumar y Cobián fue un caso de alianza continuada entre dos individuos que constituyeron cinco sociedades comunes en Sevilla; y la red Molina, un grupo inversor que actuó en Córdoba creando tres empresas comerciales, una de las cuales sí tenía carácter familiar.

\section{Especialización sectorial y estrategias empresariales}

La especialización sectorial permite reflexionar sobre las estrategias que impulsan la configuración de las redes. Fue habitual que, especialmente las más prolíficas, crearan empresas en distintos sectores, con o sin relación entre sí; en ocasiones, las actividades fueron tan diversas que no se puede adscribir la red a un sector específico, pero en la mayoría de los casos se advierte que en el origen hubo una actividad concreta, o que con el paso del tiempo la red se fue decantando por una, dándole prioridad sobre las demás. La tercera parte de las redes, entre ellas las de mayor tamaño - número de socios y número de empresas - tuvo un marcado carácter agroalimentario. Este fue el caso de González Gordon y Caballero, que constituyen ejemplos de redes integradas, ya que parte de las sociedades que crearon satisfacían las necesidades de las firmas vitivinícolas: en la red Caballero, cuatro compañías producían vino, una se dedicaba a la fabricación de botellas para envasarlo, y otra a la comercialización ${ }^{49}$. La red González Gordon giraba en torno a la empresa familiar, González Byass y a la figura de su actor principal, Manuel María González

48 Estas redes también tenían un componente técnico: en Caro, Francisco Jiménez Arévalo era arquitecto; en Baeyens, el mismo Arturo Baeyens Pleyer era ingeniero.

49 La empresa central del grupo era Luis Caballero, que compraba, criaba y exportaba vinos, licores y vinagres. 
Gordon $^{50}$; dos de las sociedades creadas por la red comercializaban vinos y destilados bajo distintas marcas, cuatro firmas se dedicaban a la explotación de fincas agrarias que proporcionaban la materia prima al negocio central, dos se dedicaban a los transportes - entre ellas una naviera-, y otra fabricaba envases y cajas de madera. En ocasiones, empresas creadas por la red participaban a su vez en la constitución de nuevas sociedades, una prueba más de la estrategia de integración vertical seguida por la red. El de González Gordon es el ejemplo de una red detrás de la cual se encuentra un grupo empresarial. Lo mismo puede decirse de la red Caballero.

GRÁFICO 3. Red tipo branch, que vinculaba empresarios gaditanos y sevillanos

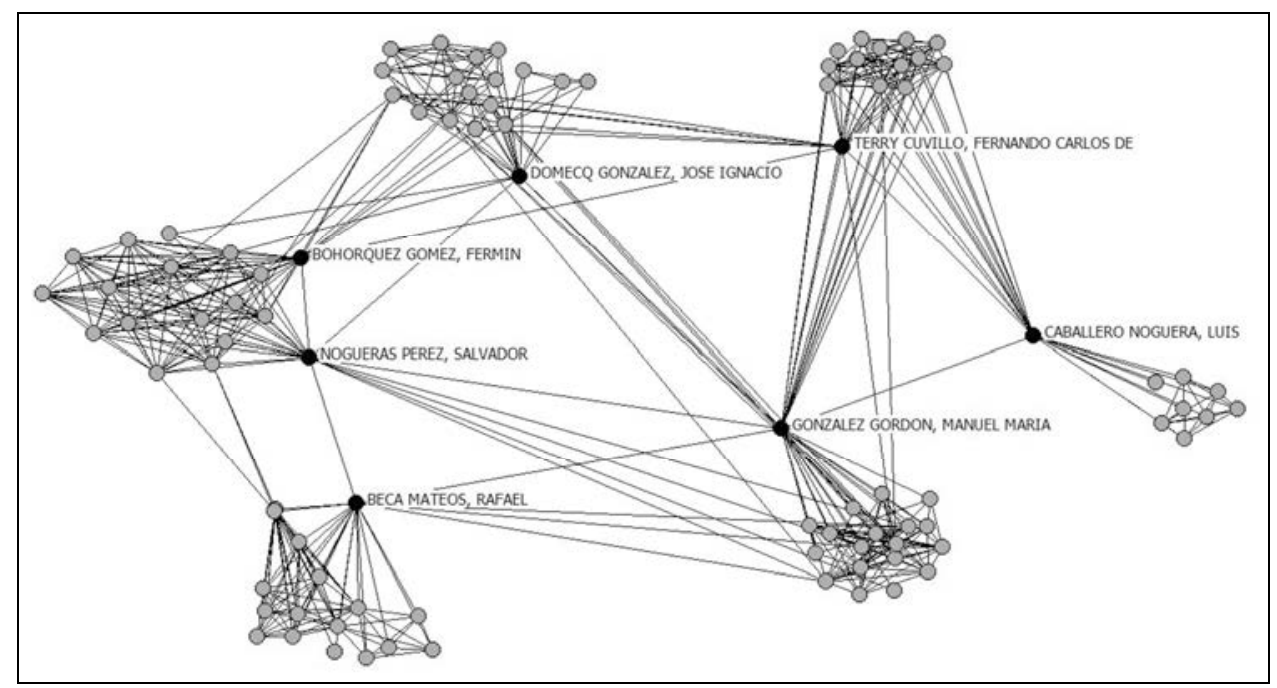

Fuente: elaboración propia. En la configuración conocida como branch, los principales actores de las subredes (marcados en negro) son los que las conectan entre sí.

Ambas redes familiares tenían más características en común, como la participación en otros negocios en sus respectivas áreas de influencia, y se relacionaban con otras redes a través de empresas comunes en las que intervenían las cabezas visibles de los grupos. Desde el punto de vista estructural ese tipo de configuración de redes que se unen con otras redes mediante vínculos entre los actores centrales de cada red se conoce como branch (gráfico 3), y fue

50 Entre 1936 y 1959, González Gordon fue el socio con mayor grado de centralidad de la red andaluza. Además de destacado empresario, fue autor de un libro de referencia sobre la historia del sector vitivinícola jerezano, GONZÁLEZ GORDON, 1935. Los orígenes de la compañía González Byass, que se remontaba a 1835, en MONTAÑÉS, 2000. 
muy frecuente entre las redes que actuaban en la mitad occidental de Andalucía - especialmente en el triángulo Sevilla, Cádiz-Jerez y Huelva - a partir de $1936^{51}$. González Gordon se relacionaba así con otras redes empresariales del marco, como las de Caballero, Domecq o Barbadillo, o con la red sevillana de Beca. Las redes jerezanas del vino eran un reflejo de una clase empresarial que conocía los mercados internacionales y con un bagaje mercantil e industrial que se transmitía de una generación a otra ${ }^{52}$.

Tres redes de promoción societaria estaban especializadas en el azúcar, dos ubicadas en el periodo anterior a la Primera Guerra Mundial, y una más después de 1936, las tres en Granada. Si las redes jerezanas del vino fueron un ejemplo de configuración tipo branch, las azucareras ayudan a entender cómo se articuló la red empresarial de Granada en su momento de esplendor, con una estructura tipo web, en la que miembros de diferentes redes se relacionan con miembros de otras redes, de carácter pluralista, sin que aparentemente prevalezca una determinada jerarquía (gráfico 4). La red López Sáez estaba formada por cinco socios, de los que tres compartían los mismos ape-

GRÁFICO 4. Red tipo telaraña vinculada al sector azucarero granadino

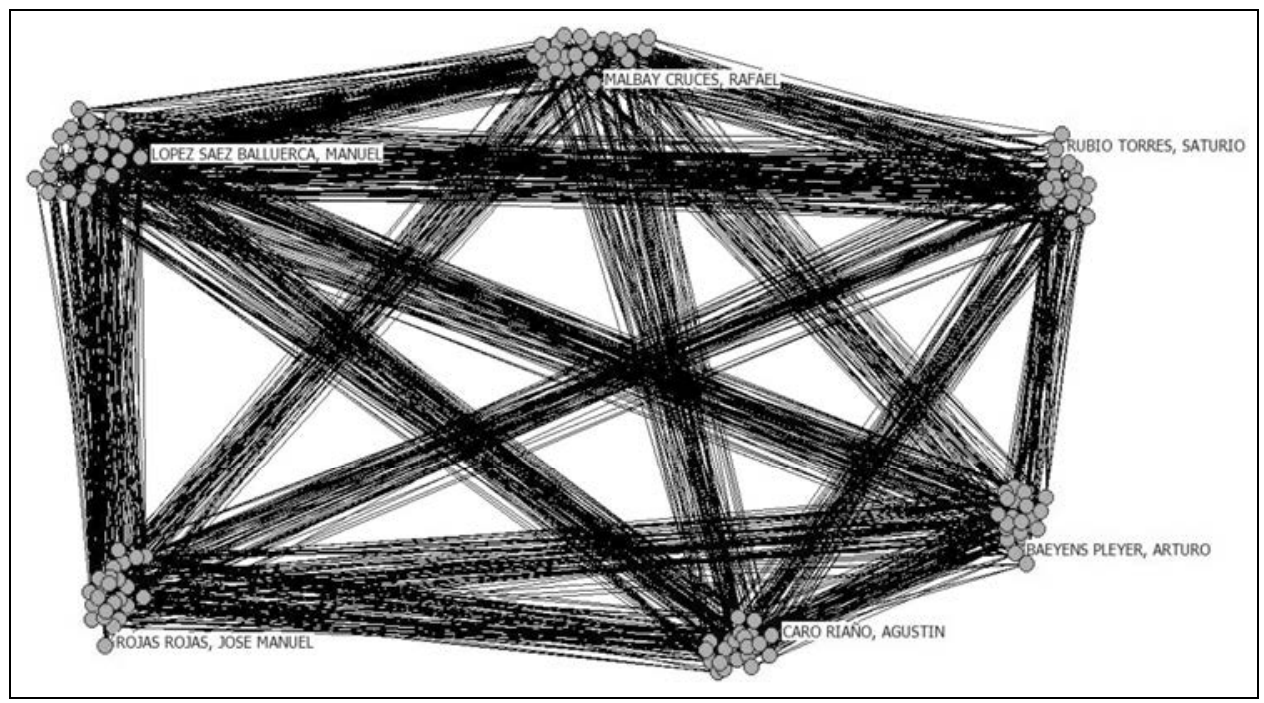

Fuente: elaboración propia. En este tipo de redes, la mayor parte de los socios se conectan a socios de otros subgrupos, sin necesidad de los actores centrales. Así, en caso de perder a uno de estos últimos, la red se recompone con facilidad, permitiendo que continúe el flujo de información.

51 Los tres tipos de configuración de redes se han explicado en el segundo apartado del texto.

52 La evolución de los empresarios y de las empresas vitivinícolas jerezanas en MALDONADO, 1998. MONTAÑÉS, 2000. LIGNON-DARMAILLAC, 2004. 
llidos; coincidían en una azucarera, López Medina e Hijos (1899) y en diferentes proyectos empresariales en los que participaba lo más destacado de la burguesía granadina, como en otras azucareras o en La Energía Eléctrica (1900), que proporcionaba electricidad a la capital y a los pueblos de la Vega. La red Rubio estaba menos diversificada y tres de las cuatro sociedades que ayudaron a crear eran azucareras, en el centro de las cuales se encontraba $R u$ bio Hermanos y Cía. (1900). Una de las empresas en cuya constitución tomaron parte fue López Medina, lo que describe una estrategia de participaciones cruzadas entre los principales empresarios e inversores del sector azucarero en la Vega.

Tan sólo una de las redes de creación de sociedades tuvo como actividad principal el aceite de oliva, a pesar de la importancia de este producto en las exportaciones agroalimentarias de la región. El papel secundario que desempeñaron los empresarios del sector oleícola en la red andaluza se ha explicado por tres razones ${ }^{53}$ : la numerosa presencia de firmas foráneas - catalanas o italianas, principalmente - que participarían en redes ajenas a Andalucía, por lo que no se pueden detectar con la fuente utilizada; la tardía llegada de estas empresas y empresarios, a partir de la Primera Guerra Mundial, lo que haría que aún no tuvieran suficiente arraigo en la región como para implicarse en otras actividades; y una última justificación, que parece la más acertada, que tiene que ver con las estrategias empresariales de un sector que, en el periodo estudiado, contaba con algunas grandes firmas, generalmente de carácter familiar ${ }^{54}$, que no necesitaban constituir nuevas sociedades ni la participación de socios ajenos para explotar un negocio que, en su mejor época, era comercializado por empresas foráneas. A estos argumentos habría que añadir el escaso grado de integración de las actividades relacionadas con la producción de aceituna y de aceite, el refino, y la comercialización.

La red especializada en el sector aceitero fue Silva, uno de los pocos casos de parejas que se han analizado. Su particularidad reside, primero, en que estuvo formada por dos subredes de dos socios cada una, para constituir unas empresas dedicadas al refino y exportación de aceite en Málaga, sociedades en las que participaron nueve miembros de la familia entre 1941 y 1950; y, segundo, en que se mantuvo al margen del componente principal de la red andaluza.

Tres redes - Lara, Luca de Tena y Navarro - que se han clasificado como agroalimentarias diversificadas, por dedicarse a distintas actividades, también estuvieron relacionadas con el aceite. La red familiar Lara creó tres sociedades en Úbeda en el periodo posterior a la Guerra Civil, una aceitera, una harinera y una fábrica de tornillos, aunque los orígenes de la actividad empresa-

53 HERNÁNDEZ, RUBIO y GARRUÉS (Murcia, 2016).

54 Sería el caso de Carbonell, Hijos de Ybarra, Pallarés Hermanos o Larios. 
rial de la familia estaban en la fabricación de aceite de oliva, orujo y jabones. La red Luca de Tena, al contrario que la anterior, estaba vinculada al componente principal. Era una manifestación del grupo empresarial Luca de Tena, con inversiones en distintos sectores económicos. Una firma, Olivarera Española (1947) se dedicaba al refino, hidrogenación y comercialización de aceites, mientras que las demás producían chocolates y bebidas. La tercera red agroalimentaria diversificada fue Navarro, que creó en Jerez de la Frontera tres sociedades en la segunda mitad de los años cincuenta, entre ellas una aceitera y una firma pesquera, de las que los tres socios se aseguraron más de la mitad de las acciones.

A medio camino entre Ayamonte y Huelva, la red Martín Navarro integraba pesca y fabricación de conservas de pescado. El núcleo eran los hermanos Martín Navarro, que hacían de puente entre una subred que actuaba en Huelva y otra que lo hacía en Ayamonte, desde los años treinta. Además de las compañías pesqueras y de las que elaboraban las conservas, la red - la mayor, en número de empresas creadas- participó en la constitución de sociedades relacionadas con ambas actividades, como un varadero para construir y reparar buques de pesca, establecimiento de frigoríficos y almacenes de mercancías y fábricas de aceite ${ }^{55}$.

La red Beca se ha catalogado como agropecuaria. Constituyó una serie de sociedades que explotaban fincas agrícolas y ganaderas en las marismas del Guadalquivir, como continuación del proyecto iniciado por Rafael Beca Mateos durante la Guerra Civil ${ }^{56}$; dos de los socios de la red eran miembros de la familia Beca, que creó un grupo empresarial integrado que incluía firmas que producían fertilizantes y vacunas para el ganado, proporcionaban suministros, fabricaban papel y procesaban los productos - sobre todo, arroz-, de las explotaciones agrarias ubicadas en la Puebla del Río; además de conectar con importantes miembros de la sociedad sevillana, el grupo Beca enlazaba con las principales redes del sistema gaditano-jerezano, a través de Marismas del Guadiamar (1947).

Tras el sector agroalimentario, fue el comercial el que predominó en un mayor número de redes. Tan sólo dos de ellas no tuvieron carácter familiar. Aunque estuvieron presentes en cuatro sistemas empresariales, la mayoría de las redes comerciales se ubicaron en Málaga, y sólo una perteneció al componente principal. Entre ellas sobresalió la red malagueña Taillefer, en la que coincidían dos subredes: una pareja, implicada en inversiones de todo tipo, y el núcleo

55 El contexto en el que actuaba esta red, la industria conservera onubense, en RÍOS, 28 (Murcia, 2002), 45-67; 29 (Barcelona, 2005), 55-87.

56 El proyecto de Beca fue continuación de anteriores empresas de capital extranjero que pretendían implantar el cultivo del algodón en las marismas. El origen del grupo estaba en la exportación de aceitunas, aunque el paso del tiempo consagró la especialización arrocera. 
familiar de los Taillefer ${ }^{57}$, vinculado al grupo empresarial del mismo nombre, especializado en firmas de importación y exportación, y que fue la red de mayor tamaño de las que no pertenecían al componente principal de la red andaluza.

Otras redes se centraron en un sector concreto diferente de la agroindustria o el comercio. A pesar de la importancia de la minería en la actividad económica de la región durante el periodo estudiado sólo aparece una red minera ${ }^{58}$. La minería es uno de los sectores más complicados para estudiar desde los registros mercantiles provinciales andaluces, pues fue frecuente que las grandes sociedades mineras se inscribieran en el registro de Madrid o en los de provincias del norte, como la de Vizcaya. Esto hace que no se puedan apreciar con precisión las conexiones entre empresarios e inversores del ramo; en los casos de las mayores compañías mineras estuvieron vinculadas mediante redes de ámbito nacional o internacional ${ }^{59}$; en otros casos, en los que las explotaciones se hacían por iniciativa local - como en el boom minero del empresariado sevillano, antes de la Primera Guerra Mundial o, en otra dimensión, en las inversiones mineras del sistema granadino en los años del azúcar-, esta actividad se diluye en redes basadas en otras especializaciones sectoriales. La única red minero-metalúrgica fue la red Figueroa, unida al componente principal y ubicada en el distrito plomífero de Linares-La Carolina ${ }^{60}$; aparte de compañías mineras y fundiciones, generó sociedades de transporte, de suministro eléctrico y de aguas. Se trataba de una manifestación de la red de negocios de los hermanos Figueroa, que sobrepasaba el ámbito del distrito y se expandía por el resto de la región y del país ${ }^{61}$. En la zona contaba con el apoyo de un tercer socio que velaba por sus intereses y que ejemplifica al intermediario, una figura relevante desde el punto de vista de la materialización de redes en territorios alejados de la residencia de los empresarios ${ }^{62}$.

Otras redes especializadas se basaban en la explotación de maderas y esparto, fabricación de material de construcción, y en el sector eléctrico. La

57 Las actividades del grupo Taillefer tenían su origen en la importación y exportación de frutos y maderas que inició Augusto Taillefer Panigua, hijo de un ingeniero agrónomo francés que se instaló en Málaga a principios de los años sesenta del siglo XIX.

58 La minería andaluza en los siglos XIX y XX, en SÁNCHEZ PICÓN, 2013: 29-43.

59 Como la red de los Rothschild, estudiada por LÓPEZ MORELL y O'KEAN, 50 (Oxford, 2008): 163-184.

60 Las características de las empresas de la minería del plomo, en SÁNCHEZ PICÓN, 29 (Barcelona, 2005): 13-54.

61 Gonzalo y Álvaro de Figueroa y Torres eran propietarios de minas de plomo en el sureste del país como consecuencia de los negocios emprendidos por su abuelo en las primeras décadas del siglo XIX, estudiados por CHASTAGNARET, 1 (Barcelona, 1992): 11-38. Álvaro, conde de Romanones, fue una figura central en la vida política del país en el primer tercio del siglo XX.

${ }_{62}$ Se trataba de Antonio Conejero, que provenía de una familia vinculada a la actividad minera y que fue alcalde de Linares. 
última merece un comentario, por el componente tecnológico de sus socios: estaba formada por Rafael Malbay, otros dos ingenieros como él, y un arquitecto; en la transición de los siglos XIX al XX, coincidiendo con el auge del azúcar en la vega granadina desarrollaron distintos proyectos, relacionados con la expansión de la electricidad, la minería y las construcciones mecánicas, a las que aplicaban sus competencias técnicas ${ }^{63}$.

Pero también hubo redes que no presentaron una especialización sectorial clara, en algunos casos porque eran redes de inversión - socios predominantemente capitalistas que financiaban distintas iniciativas ajenas-, y en otros porque la capacidad empresarial de sus miembros las conducía a proyectos con poca relación entre sí. Dos de las redes inversoras coincidieron con la de Malbay y otras redes implicadas en la configuración de la red tipo web granadina. Estuvieron formadas por empresarios y propietarios residentes en Granada, algunos de ellos con formación técnica, y vinculados a los negocios mercantiles más interesantes de la zona, entre ellos las azucareras.

El resto de las redes que no estaban especializadas en un sector económico concreto se localizaron en Cádiz-Jerez de la Frontera y Sevilla. En el primer sistema empresarial, la red no familiar Abarzuza estaba formada por comerciantes y propietarios gaditanos y sevillanos, que invirtieron en distintos negocios de la zona desde la década de 1880, aportando su capacidad financiera. La red denominada Osborne también estaba formada por socios de las provincias de Sevilla y Cádiz; su configuración permite diferenciar entre redes de creación de sociedades y grupos empresariales, ya que en ella confluían las actividades del grupo Osborne y de una rama de la familia Benjumea: los negocios donde coincidían se correspondían con la especialización originaria del primer grupo, vino y fabricación de cerveza - La Cruz del Campo-, aunque invirtieron en toda clase de actividades comerciales e industriales. Pero la característica más notable de esta red es estructural, ya que desempeñó el papel de eslabón o bisagra ${ }^{64}$, que facilitaba la unión de las subredes sevillanas del componente principal en el periodo posterior a 1936.

En los mismos años actuó la pareja formada por Prudencio Pumar y Luis Cobián, promotores de Hilaturas y Tejidos Andaluces (HYTASA), proyecto que pretendía revitalizar la industria textil en la región ${ }^{65}$. La última red fue otra pareja, Lúquez, que invirtió en distintos negocios de su entorno, en el sistema sevillano, sin relación con el componente principal, pero que se men-

63 Al margen de la red y del sistema empresarial granadino, Malbay creó sociedades en distintas partes de la región, en las que residía como consecuencia de su profesión, explotando las oportunidades de negocio de la zona, del tipo que fuesen: construcciones mecánicas en Jaén y en Úbeda, fábricas de orujo en Beas de Segura o comercio de aguardientes en Ronda.

64 Como la red Martín Navarro.

65 Sobre HYTASA, véase FERNÁNDEZ ROCA, 1998. 
ciona porque muestra cómo actuaban las redes de inversión pequeñas en la región: los miembros de la red tenían como socios en dos empresas a otros familiares - primos en este caso-, y el grupo inversor enlazaba a su vez con otro grupo empresarial formado por dos sociedades, en cuyas constituciones participaban hasta nueve hermanos.

\section{Componente principal y tamaño}

De las 30 redes identificadas, 18 pertenecían al componente principal, precisamente las que tenían un mayor número de miembros y las que generaron más compañías. Las redes ajenas al componente principal actuaron en áreas geográficas limitadas y, salvo en un caso, su importancia empresarial fue modesta $^{66}$.

El tamaño de la red se determina por el número de actores o socios que crearon de manera conjunta al menos tres empresas. La red mayor fue González Gordon, formada por ocho individuos, seguida de Martín Navarro, con seis socios. Las redes más pequeñas fueron parejas de dos socios.

El tamaño de la red también se puede medir por el número de empresas constituidas por sus miembros. Entre las 30 redes identificadas crearon un total de 219 firmas; la más prolífica fue Martín Navarro, responsable de 16 sociedades, seguida de González Gordon, que creó 14, y de otras seis redes que crearon al menos nueve compañías. Las redes más pequeñas registraron tres empresas.

\section{Periodo, años de actividad y antecedentes}

El periodo en el que actuaron las redes se ha determinado a partir de la fecha de constitución de la mayoría de sus empresas; de las 30 redes, ocho desarrollaron su acción con anterioridad a la Primera Guerra Mundial, una entre 1914 y 1935, y 21 a partir de 1936. Aunque la mayor parte de los socios de las redes contaban con precedentes familiares en el ámbito empresarial regional, la columna «antecedentes» del cuadro 2 se refiere exclusivamente a la creación de sociedades por los miembros de la red, evaluando si habían comenzado antes de la etapa en la que se ha ubicado aquella. Esto permite conocer, por ejemplo, si en una misma red convivieron individuos de distintas generaciones. Sólo siete redes contaron con antecedentes (aunque las del primer periodo estaban limitadas por la disponibilidad de información). La edad

${ }^{66}$ La excepción fue la red malagueña Taillefer. 
de la red está definida por el número de años que separan la primera y la última empresa creada por algún miembro del grupo: las redes más longevas estaban asociadas a algunas de las principales familias del negocio vitivinícola del Marco de Jerez, como González Gordon y Caballero.

\section{Forma jurídica}

La forma jurídica de las empresas suele utilizarse como indicador de modernización de una economía: formas personalistas y de responsabilidad ilimitada se asocian a menor grado de desarrollo, y sociedades de responsabilidad limitada suelen vincularse a una mayor modernización. Entre las empresas creadas por las redes fue predominante la sociedad anónima: esto ocurrió en 22 casos; en total, en 28 de las 30 redes prevalecían las formas de responsabilidad limitada. Se trata de una evidencia de la capacidad de conexión de esta forma societaria, que permite la participación de un elevado número de socios a los que ofrece unas garantías jurídicas (reduciendo el riesgo), al tiempo que posibilita reunir un capital social importante.

\section{CONCLUSIONES}

Este trabajo ofrece dos contribuciones a la historiografía económica y empresarial española: por un lado, muestra las posibilidades del análisis de redes sociales como herramienta metodológica para los investigadores; por otro, se presenta por primera vez, y de forma desagregada, el conjunto de redes empresariales de carácter formal que operaron en una región en un periodo prolongado de tiempo.

Como se decía en la introducción, a pesar de la importancia de los empresarios en el desarrollo económico, son necesarias unas condiciones favorables previas que no se dieron en Andalucía entre los años 1886-1959. Para impulsar la segunda fase de la revolución industrial, que coincide en la región con el periodo estudiado, habría sido conveniente una sociedad con menos desequilibrios socioeconómicos, mayores niveles de alfabetización y mayor proximidad a los centros de consumo, de poder y de toma de decisiones.

Los empresarios que actuaron en Andalucía fueron capaces de articular una gran red de creación de sociedades mercantiles, que evolucionó con el paso del tiempo. Esta red permitió la transmisión de la información necesaria para descubrir y explotar oportunidades de negocio, dentro de las limitaciones impuestas por el marco económico e institucional. La red agrupó a los empresarios más dinámicos que, no obstante, quedaron prácticamente excluidos de 
los negocios más rentables que, en distintos momentos, ofreció la región, como la minería, la exportación de aceite de oliva o la transformación y exportación del corcho, sectores que requerían el conocimiento y posicionamiento en los mercados exteriores y, en el caso de la minería, de grandes inversiones de capital. Estas actividades, por lo tanto, quedaron en manos de compañías extranjeras o radicadas en otras regiones españolas.

La contribución de la red al desarrollo económico andaluz se aprecia mejor cuando se descompone en redes más pequeñas: la mitad de ellas se dedicaban principalmente a negocios relacionados con la agroindustria o a la comercialización de productos agroalimentarios, y la inmensa mayoría surgía a partir de dichas especializaciones. En cambio, sólo una red tuvo una marcada vocación minero-metalúrgica - y era la manifestación de una red de carácter internacional que superaba el marco geográfico andaluz-, en contraste con la importancia de la actividad extractiva para la economía regional, al menos hasta la Primera Guerra Mundial.

El estudio cualitativo de la red y de las subredes ha puesto de manifiesto un elemento relevante: la escasez de «vínculos débiles», aquellos actores que introducen ideas e innovaciones en una sociedad, contribuyendo al crecimiento económico. Las redes andaluzas se desarrollaron a partir de lazos de carácter familiar, de amistad y de círculos locales. Sólo unos pocos socios fundadores de empresas ejercían la función de conectar las redes entre sí, y entre ellos predominaban individuos foráneos, por lo general hombres de la banca o representantes de grupos empresariales nacionales. Pero, hay que insistir, fueron pocos, lo que no favoreció la modernización económica de la región.

El análisis de las redes empresariales también ha proporcionado información sobre su configuración formal, además de sobre otros elementos como los resultados de las estrategias empresariales, la longevidad o las formas jurídicas predominantes. Se trata de un primer paso, que habrá que completar en el futuro para comprobar, mediante investigación cualitativa, la implicación de cada una de las subredes en el desarrollo local, integrando elementos de carácter político, social y cultural. Otra línea de trabajo debe buscar las conexiones entre las redes andaluzas y la red corporativa nacional, que agrupaba a la élite de directivos y propietarios de las mayores empresas españolas, para verificar si, como parece, la primeras apenas participaron de la segunda, lo que reforzaría el argumento de la lejanía de la región con respecto a los centros de poder económico del país.

Una última reflexión: los tipos de redes que se han presentado en este texto están, como se ha dicho, determinados por el carácter de la economía andaluza, y por el hecho de que no se produjera en la región un despegue industrial. Ahora bien, en las regiones industrializadas, las redes empresariales han contribuido a la generación de nuevos ciclos de actividad económica, vincu- 
lados a la tercera revolución tecnológica. La pregunta que cabe plantear es si, en la actualidad, una región puede modernizarse tecnológicamente sin la existencia previa de redes empresariales.

ANEXO 1. Las mayores empresas registradas en Andalucía, en función del capital neto

\begin{tabular}{|c|c|c|c|c|}
\hline $\mathbf{A}$ & $1886-1913$ & SECTOR & $\begin{array}{l}\text { CAPITAL } \\
\text { NETO* }\end{array}$ & RED** \\
\hline 1 & The Morenilla Linares Limited & Minería & 42,5 & - \\
\hline 2 & $\begin{array}{c}\text { Banco Agrícola de Levante de } \\
\text { Andalucía }\end{array}$ & Banca & 25,1 & - \\
\hline 3 & Hijos de Larios & Comercio & 25,0 & - \\
\hline 4 & $\begin{array}{c}\text { The Seville Waterworks Com- } \\
\text { pany Limited }\end{array}$ & Agua & 16,9 & - \\
\hline 5 & Sociedad Azucarera Larios & Industria Agroalimentaria & 16,6 & - \\
\hline 6 & $\begin{array}{c}\text { Compañía Limitada de Tranvías } \\
\text { de Málaga }\end{array}$ & Ferrocarriles y tranvías & 15,7 & - \\
\hline 7 & Banco de Andalucía & Banca & 15,6 & Figueroa \\
\hline 8 & $\begin{array}{c}\text { Compañía Sevillana de Electri- } \\
\text { cidad }\end{array}$ & Electricidad y Gas & 14,2 & $\mathrm{CP}$ \\
\hline 9 & $\begin{array}{l}\text { La Constructora Naval Españo- } \\
\text { la }\end{array}$ & Material de Transporte & 13,3 & $\mathrm{CP}$ \\
\hline 10 & González Byass y Compañía & Industria Agroalimentaria & 12,8 & $\mathrm{CP}$ \\
\hline 11 & $\begin{array}{l}\text { Minas del Castillo de Las Guar- } \\
\text { das y Ferrocarril a Sevilla }\end{array}$ & Minería & 10,4 & $\mathrm{CP}$ \\
\hline 12 & $\begin{array}{c}\text { Sociedad Agrícola Industrial del } \\
\text { Guadalete }\end{array}$ & Industria Agroalimentaria & 9,6 & Abárzuza \\
\hline 13 & $\begin{array}{c}\text { Sociedad Industrial y Agrícola } \\
\text { del Guadiaro }\end{array}$ & Industria Agroalimentaria & 9,3 & - \\
\hline 14 & Altos Hornos de Andalucía & Productos Metálicos & 8,2 & - \\
\hline 15 & $\begin{array}{c}\text { Sociedad Minera y Metalúrgica } \\
\text { de Peñarroya }\end{array}$ & Productos Metálicos & 8,2 & - \\
\hline
\end{tabular}

Fuente: elaboración propia. A: posición en el ránking. Capital neto*: resultado de la suma de capital de constitución, ampliación de capital y emisión de obligaciones, al que se restan las reducciones de capital. Se expresa en millones de pesetas constantes de 1913. Red**: si la empresa está constituida por socios incluidos en el componente principal (CP) de la red; se indica si, además, se encuentra en una de las subredes analizadas individualmente a lo largo del texto. 
ANEXO 2. Las mayores empresas registradas en Andalucía, en función del capital neto

\begin{tabular}{|c|c|c|c|c|}
\hline $\mathbf{A}$ & 1914-1935 & SECTOR & $\begin{array}{l}\text { CAPITAL } \\
\text { NETO* }\end{array}$ & RED** \\
\hline 1 & Compañía Sevillana & Electricidad y Gas & 98,1 & $\mathrm{CP}$ \\
\hline 2 & The Morenilla Linares Limited & Minería & 42,5 & - \\
\hline 3 & $\begin{array}{c}\text { Tranvía de Cádiz a San Fer- } \\
\text { nando y Carraca }\end{array}$ & Ferrocarriles y tranvías & 22,4 & $\mathrm{CP}$ \\
\hline 4 & $\begin{array}{c}\text { Manufacturas de Corcho Arms- } \\
\text { trong }\end{array}$ & Madera, corcho & 21,2 & - \\
\hline 5 & $\begin{array}{c}\text { Bética S.A. Cooperativa Agrí- } \\
\text { cola Industrial }\end{array}$ & Industria Agroalimentaria & 19 & $\begin{array}{l}\text { López } \\
\text { Sáez }\end{array}$ \\
\hline 6 & $\begin{array}{c}\text { Fuerzas Motrices del Valle de } \\
\text { Lecrín }\end{array}$ & Electricidad y Gas & 18,6 & $\mathrm{CP}$ \\
\hline 7 & $\begin{array}{l}\text { The Seville Waterworks Com- } \\
\text { pany Limited }\end{array}$ & Agua & 16,9 & - \\
\hline 8 & Sociedad Azucarera Larios & Industria Agroalimentaria & 16,6 & - \\
\hline 9 & $\begin{array}{l}\text { Compañía Limitada de } \\
\text { Tranvías de Málaga }\end{array}$ & Ferrocarriles y tranvías & 16,1 & - \\
\hline 10 & $\begin{array}{l}\text { Sociedad Española de Tejidos } \\
\text { Industriales }\end{array}$ & Industria Textil & 15,5 & - \\
\hline 11 & $\begin{array}{c}\text { Sociedad Hidroeléctrica del } \\
\text { Chorro }\end{array}$ & Electricidad y Gas & 13,7 & - \\
\hline 12 & $\begin{array}{l}\text { La Constructora Naval Españo- } \\
\text { la }\end{array}$ & Material Transporte & 13,3 & $\mathrm{CP}$ \\
\hline 13 & González Byass y Compañía & Industria Agroalimentaria & 12,8 & $\mathrm{CP}$ \\
\hline 14 & Ybarra y $\mathrm{C}^{\mathrm{a}}$ & Transporte & 12,8 & $\mathrm{CP}$ \\
\hline 15 & $\begin{array}{l}\text { Compañía General de Electri- } \\
\text { cidad }\end{array}$ & Electricidad y Gas & 11,3 & - \\
\hline
\end{tabular}

Fuente: elaboración propia. A: posición en el ránking. Capital neto*: resultado de la suma de capital de constitución, ampliación de capital y emisión de obligaciones, al que se restan las reducciones de capital. Se expresa en millones de pesetas constantes de 1913. Red**: si la empresa está constituida por socios incluidos en el componente principal (CP) de la red; se indica si, además, se encuentra en una de las subredes analizadas individualmente a lo largo del texto. 
ANEXO 3. Las mayores empresas registradas en Andalucía, en función del capital neto

\begin{tabular}{|c|c|c|c|c|}
\hline A & $\mathbf{1 9 1 4 - 1 9 3 5}$ & SECTOR & $\begin{array}{c}\text { CAPITAL } \\
\text { NETO* }\end{array}$ & RED** \\
\hline 1 & Compañía Sevillana de Electricidad & Electricidad y Gas & 364 & CP \\
\hline 2 & Sociedad Hidroeléctrica del Chorro & Electricidad y Gas & 65,8 & - \\
\hline 3 & Ybarra y C & Transporte & 26,3 & CP \\
\hline 4 & $\begin{array}{c}\text { Hilaturas y Tejidos Andaluces, HY- } \\
\text { TASA }\end{array}$ & I. Textil & 24,5 & $\begin{array}{c}\text { Pumar y } \\
\text { Cobián }\end{array}$ \\
\hline 5 & $\begin{array}{c}\text { Tranvía de Cádiz a San Fernando y } \\
\text { Carraca }\end{array}$ & FFCC & 22,4 & CP \\
\hline 6 & Manufacturas de Corcho Armstrong & I. Madera y Muebles & 21,2 & - \\
\hline 7 & $\begin{array}{c}\text { Bética S.A. Cooperativa Agrícola } \\
\text { Industrial }\end{array}$ & I. Agroalimentaria & 19 & $\begin{array}{c}\text { López } \\
\text { Sáez }\end{array}$ \\
\hline 8 & Fuerzas Motrices del Valle de Lecrín & Electricidad y Gas & 18,6 & CP \\
\hline 9 & The Seville Waterworks Company & & 16,9 & - \\
\hline 10 & Limited & Agua & 11,9 & CP \\
\hline 11 & Sociedad Azucarera Larios & I. Agroalimentaria & 16,6 & - \\
\hline 12 & Pedro Domecq & I. Agroalimentaria & 15,8 & - \\
\hline 13 & La Constructora Naval Española & I. Material Transporte & 13,3 & CP \\
\hline 14 & González Byass y Compañía & I. Agroalimentaria & 12,8 & CP \\
\hline 15 & $\begin{array}{c}\text { Sociedad Andaluza de Cementos } \\
\text { Lortland }\end{array}$ & I. Cemento & 15,7 & Osborne \\
\hline
\end{tabular}

Fuente: elaboración propia. A: posición en el ránking. Capital neto*: resultado de la suma de capital de constitución, ampliación de capital y emisión de obligaciones, al que se restan las reducciones de capital. Se expresa en millones de ptas. constantes de 1913. Red**: si la empresa está constituida por socios incluidos en el componente principal (CP) de la red; se indica si, además, se encuentra en una de las subredes analizadas individualmente a lo largo del texto. 


\section{BIBLIOGRAFÍA}

Alfani, Guido y Gourdon, Vincent, «Entrepreneurs, formalization of social ties, and trustbuilding in Europe (fourteenth to twentieth centuries)», Economic History Review, 65 (Oxford, 2012): 1.005-1.028.

Badía, Marc, Blasco, Yolanda, Lozano, Sergi y Soler, Raimon, «Redes sociales y negocios. La red de inversión del banco de Barcelona en la economía catalana a mediados del siglo XIX», Investigaciones de Historia Económica, 9 (Madrid, 2013): 143-154.

Bernal, Antonio, Florencio, Antonio y Martínez Ruiz, José I., El Empresariado Andaluz en Perspectiva Histórica, Sevilla, Escuela Andaluza de Economía, 2010.

Bertrand, Michelle, Guzzi-Heeb, Sandro y Lemercier, Claire, «Introducción: ¿en qué punto se encuentra el análisis de redes en Historia?», Redes Revista hispana para el análisis de redes sociales [en línea], 21 (2011), disponible en: http://revistes. uab.cat/redes/article/view/v21-bertran-guzziheeb-lemercier [consultado el 24 de octubre de 2015].

Borgatti, Steve y Halgin, Daniel, «On Network Theory», Organization Science, 22 (New York, 2011): 1.168-1.181.

Cárdenas, Julián, "Varieties of corporate networks: Network analysis and fsQCA», International Journal of Comparative Sociology, 53 (Dorchester, 2012): 298-322.

Casson, Mark, «Entrepreneurial Network in International Business», Business and Economic History, 26/2 (Williamsburg, 1997): 811-823.

Casson, Mark, Entrepreneurship. Theory, Networks, History, Northampton, Edward Elgar, 2010a.

Casson, Mark, «Networks in Economics and Business History: A Theoretical Perspective», en Paloma Fernández Pérez y Mary Rose (eds.), Innovation and Entrepreneurial Networks in Europe, New York, Routledge, 2010b: 14-40.

Casson, Mark y Della Giusta, Marina, «Entrepreneurship and Social Capital. Analysing the Impact of Social Networks on Entrepreneurial Activity from a Rational Perspective», International Small Business Journal, 25 (New York, 2007): 220-244.

Castejón, Rafael, Génesis y desarrollo de una sociedad mercantil e industrial en Andalucía: la Casa Carbonell de Córdoba (1866-1918), Córdoba, Monte de Piedad-Caja de Ahorros de Córdoba, 1977.

Chastagnaret, Gérard, «Marsella en la economía internacional del plomo», Revista de Historia Industrial, 1 (Barcelona, 1992): 11-38.

Fernández Pérez, Paloma, El rostro familiar de la metrópoli: redes de parentesco y lazos mercantiles en Cádiz, 1700-1812, Madrid, Siglo XXI, 1997.

Fernández Pérez, Paloma y Colli, Andrea (eds.), The Endurance of Family Businesses. A Global Overview, Cambridge, Cambridge University Press, 2013.

Fernández Roca, Francisco, HYTASA (1937-1980): Orto y ocaso de la industria textil sevillana, Sevilla, Diputación de Sevilla, 1998.

Garrués, Jósean y Rubio, Juan A., «La formación del espacio empresarial andaluz», Scripta Nova, Revista Electrónica de Geografía y Ciencias Sociales [en línea], 
XVI/404 (2012), disponible en: http://www.ub.edu/geocrit/sn/sn404.htm [consultado el 24 de octubre de 2015].

Garrués, Jósean y Rubio, Juan A., «Empresarialidad y redes empresariales», en Andrés Sánchez Picón (coord.), Industrialización y desarrollo económico en Andalucía, Sevilla, Centro de Estudios Andaluces, 2013: 139-161.

Garrués, Jósean, Rubio, Juan A. y Hernández, Salvador, «Empresarios y redes empresariales en la Andalucía contemporánea», Revista de Historia Industrial, 51 (Barcelona, 2013): 109-142.

González Gordon, Manuel, Jerez-Xerez-Scheris. Apuntes sobre el origen de esta ciudad, su historia y su vino, Jerez de la Frontera, Imprenta Padura, 1935.

Granovetter, Mark, «The strength of weak ties», American Journal of Sociology, 78 (Chicago, 1973): 1.360-1.380.

Granovetter, Mark, «Economic Action and Social Structure: The Problem of Embeddedness», American Journal of Sociology, 91 (Chicago, 1985): 481-510.

Granovetter, Mark, «Economic Institutions as Social Constructions: A Framework for Analysis», Acta Sociologica, 35 (New York, 1992): 3-11.

Hernández, Salvador, Rubio, Juan A. y Garrués, Jósean, «A un panal de rica miel... Empresas y empresarios en la exportación de aceite de oliva andaluz, 18861936», Historia Agraria, Revista de Agricultura e Historia Rural, 70 (Murcia, 2016): 43-78.

Jiménez Araya, Tomás, «Formación de capital y fluctuaciones económicas. Materiales para el estudio de un indicador: creación de sociedades mercantiles en España entre 1886 y 1970», Hacienda Pública Española, 27 (Madrid, 1974): 137-185.

Jiménez Blanco, José I., «Las raíces agrarias del crecimiento económico andaluz, 1800-1936», Documento de Trabajo de la AEHE [en línea], 1203 (2012), disponible en: http://www.aehe.net/2012/05/dt-aehe-1203.pdf [consultado el 24 de octubre de 2015].

Leff, Nathanael, «Industrial Organization and Entrepreneurship in Developing Countries: The Economic Groups», Economic Development and Cultural Change, 26 (Chicago, 1978): 661-675.

Lignon-Darmaillac, Sophie, Les grandes maisons du vignoble de Jerez (1834-1992), Madrid, Casa de Velázquez, 2004.

Lizárraga, Carmen, El progreso económico de Andalucía en el siglo XX, Sevilla, Instituto de Estadística de Andalucía, 2009.

López Morell, Miguel A. y O’kean, José, «A stable network as a source of entrepreneurial opportunities: The Rothschilds in Spain, 1835-1931», Business History, 50 (Oxford, 2008): 163-184.

Maldonado, Javier, La formación del capitalismo en el marco del Jerez. De la vitivinicultura tradicional a la agroindustria vinatera moderna (siglos XVIII y XIX), Madrid, Huerga y Fierro, 1998.

Martín, Manuel, Azúcar y descolonización. Origen y desenlace de una crisis agraria en la Vega de Granada. El Ingenio de San J., 1882-1904, Granada, Instituto de Desarrollo Regional, 1982. 
Martín, Manuel, Azúcar e intervención económica en España: la fábrica azucarera San Isidro, 1904-1984, Granada, Universidad de Granada, 2009.

Martín, Manuel, Garrués, Jósean y Hernández, Salvador (eds.), El Registro Mercantil: una fuente para la historia económica, Granada, Universidad de Granada, 2003.

McNeill, John y McNeill, William, Las redes humanas. Una historia global del Mundo, Barcelona, Crítica, 2004.

Milgram, Stanley, «The Small World Problem», Psychology Today, 1 (New York, 1967): 61-67.

Montañés, Enrique, La empresa exportadora del Jerez. Historia económica de González Byass, 1835-1885, Jerez de la Frontera, Universidad de Cádiz, 2000.

Nadal, Jordi y Sudrià, Carles, «La controversia en torno al atraso económico español en la segunda mitad del siglo XIX», Revista de Historia Industrial, 3 (Barcelona, 1993): 199-227.

Núñez, Gregorio, «Tejiendo redes empresariales en Andalucía Oriental. Vida y obra de Alfredo Velasco y Sotillos (1872-1936)», Cuadernos de trabajo del Grupo de Estudios Históricos sobre la empresa [en línea], 5/5 (2005), disponible en: http://www.ugr.es/ teoriahe/RePEc/gra/wpaper/thepapers05_05.pdf [consultado el 24 de octubre de 2015].

Parejo, Antonio, Málaga y los Larios. Capitalismo industrial y atraso económico (1875-1914), Málaga, Editorial Arguval, 1990.

Parejo, Antonio, «Empresa y empresarios en Andalucía. Una perspectiva histórica», en José L. García Ruiz y Carles Manera (eds.), Historia Empresarial de España. Un enfoque regional, Madrid, Lid, 2006: 425-448.

Parejo, Antonio, Historia económica de Andalucía contemporánea, Madrid, Síntesis, 2009.

Parejo, Antonio, «Introducción», en Antonio Parejo (coord.), Grandes empresarios andaluces, Madrid, Lid, 2011: 11-23.

Parson, Mike y Rose, Mary, «Innovation, Entrepreneurship and Networks. A Dance of Two Questions», en Paloma Fernández Pérez y Mary Rose (eds.), Innovation and Entrepreneurial Networks in Europe, Londres, Routledge, 2010: 41-60.

Prados de la Escosura, Leandro, El progreso económico de España (1850-2000), Bilbao, Fundación BBVA, 2003.

Ríos, Segundo, «La industrialización de la pesca en la provincia de Huelva (18001930)», Historia Agraria, Revista de Agricultura e Historia Rural, 28 (Murcia, 2002): 45-67.

Ríos, Segundo, «Origen y desarrollo de la gran industria de conservas de pescado en Andalucía (1879-1936)», Revista de Historia Industrial, 29 (Barcelona, 2005): 55-87.

Roldán, Santiago, García Delgado, José L. y Muñoz, Juan, La formación de la sociedad capitalista en España, 1914-1920, Madrid, CECA, 1973.

Rubio, Juan A., Andalucía durante la segunda revolución tecnológica: ciclos de inversión, sociedades mercantiles y grupos empresariales, Granada, Universidad de Granada, 2014. 
Rubio, Juan A., «Redes empresariales y empresarialidad en una región atrasada: Andalucía, 1886-1959», en Joséan Garrués y Juan A. Rubio (coords.), Haciendo Historia Económica: nuevas investigaciones, nuevos investigadores, Granada, Universidad de Granada, 2015: 151-163.

Rubio, Juan A. y Garrués, Jósean, «Economic and Social Power in Spain: Corporate Networks of Banks, Utilities and other Large Companies (1917-2009)», Business History, 58 (Oxford, 2016): 858-879.

Rubio, Juan A. y Garrués, Jósean, «Sistemas empresariales locales y territorios de progreso en Andalucía, 1886-1959», Revista de Historia Industrial, 68 (Barcelona, 2017): 81-117.

Sánchez Picón, Andrés, «Un imposible capitalismo: empresas, tradiciones organizativas y marco institucional en la minería del plomo española del siglo XIX», Revista de Historia Industrial, 29 (Barcelona, 2005): 13-54.

Sánchez Picón, Andrés, «El protagonismo andaluz en la expansión minera (siglos XIX y XX)», en Andrés Sánchez Picón (coord.), Industrialización y desarrollo económico en Andalucía, Sevilla, Centro de Estudios Andaluces, 2013: 29-43.

Tafunell, Xavier, «Empresa y bolsa», en Albert Carreras y Xavier Tafunell (coords.), Estadísticas Históricas de España. Siglos XIX-XX, Madrid, Fundación BBVA, 2005: 707-834.

Tortella, Gabriel, «La iniciativa empresarial, factor escaso en la España contemporánea», en Francisco Comín y Pablo Martín Aceña (eds.), La empresa en la historia de España, Madrid, Civitas, 1996: 49-60.

Valdaliso, Jesús, «El espíritu emprendedor en España: un análisis histórico», en Miguel Sastre (coord.), La empresa y el espíritu emprendedor de los jóvenes, Madrid, Ministerio de Educación, 2005: 115-145.

Valdaliso, Jesús y García Ruiz, José L., «El espíritu empresarial en la historia económica española», Revista de Historia Industrial, 51 (Barcelona, 2013): 15-18.

Wasserman, Stanley y Faust, Katherine, Análisis de redes sociales. Métodos y aplicaciones, Madrid, Centro de Investigaciones Sociológicas, 2013.

Watts, Duncan, Six Degrees: The Science of a Connected Age, Londres, William Heinemann, 2003.

Recibido: $10 / 11 / 2015$

Aprobado: 21/10/2016 